\title{
Project Based Learning experience with engineering students for the design of steel structures
}

\section{Ibáñez, Carmen ${ }^{\text {; }}$ Hernández-Figueirido, David ${ }^{a}$}

${ }^{a}$ Department of Mechanical Engineering and Construction, Universitat Jaume I, Castellón de la Plana (Spain)

\begin{abstract}
This work describes the Project Based Learning (PBL) experience carried out with engineering students in the field of steel structures design during the academic year 2016-2017 at the Universitat Jaume I of Castellón de la Plana (Spain). This experience is integrated in the Master of Science in Industrial Engineering.
\end{abstract}

The experience consists of simulating the activity of a technical office dedicated to the development of structural projects. A real situation comprising the design and calculation of an industrial building for a costumer is presented to the students. Some geometrical aspects according to the customer desires and the industrial process to be set at the building are specified. The students are organized in groups and have to work in a project to develop a competitive solution to this real necessity within deadline.

Finally, a survey is conducted to evaluate both the impact of this experience in the learning process and the students' degree of satisfaction with respect to this technique.

The results of the survey show that PBL promotes the technical training of the students in this field and encourages the development of transversal skills, enhancing, at the same time, their motivation.

Keywords: Project Based Learning; Engineering students; Design of structures; Structural Project. 


\section{Introduction}

In these days, as a result of the European Higher Education Area (EHEA) harmonization process, the necessity of new student-centered models and techniques has increased. Students not only must acquire the specific skills related to the field of knowledge of the degree but also must develop transversal skills, highly demanded and appreciated by employers and companies.

In fact, in the Bucharest Communiqué (2012), it was explicitly pointed out that nowadays graduates need to combine transversal skills and competences with up-to-date subjectspecific knowledge in order to contribute to the needs of society and labor market. Therefore, these transversal skills are mainly related to continuous learning, teamwork and autonomy, critical thinking, planning and communication skills (Lacuesta et al., 2009).

Thus, the application of innovative learning techniques such as Project Based Learning (PBL) is allowing the higher education to adapt to this new scenario (Gwen, 2003). PBL is a methodology which focuses on the students who, in small groups, must carry out the development of a project to give solution to a real necessity. This methodology was successfully applied in the field of medicine at 70 's to encourage unmotivated students and it became soon very popular among lecturers worldwide (Woods et al., 2000). Note that the initials PBL can be also found in the literature to refer to Problem Based Learning, a different teaching approach.

Several are the skills and capabilities that PBL allows to develop and enhance such as analysis and synthesis, research, knowledge transfer, critical thinking, individual and group responsibilities, treatment of multiple information sources, working in group, planning and organizational skills or decision making (de Miguel, 2005). During all the process, the students have to work in groups, planning their steps, distributing tasks, researching and making an analysis of all the variables involved. To successfully accomplish the activity, the student must adopt an active attitude and interact with others to contrast ideas and opinions. Actually, the basis of this method lies in thinking over the own knowledge to develop new skills and gain expertise (learning to learn).

At the present time, PBL is considered as one of the learning based methods for the new models in higher education. Comparisons made with traditional teaching methods reveal a higher level of learning when PBL is applied (Maldonado, 2008). As a consequence, the number of practical cases about the application of this technique has increased, and numerous examples can be found in literature where PBL has been integrated in technical degrees with satisfactory results. Among others, experiences with telecommunications, civil or mechanical engineering students can be found (Alcober, 2003; Rodríguez, 2015; Tejero, 2015). 
Adopting the PBL technique implies the possibility to put into practice and develop several skills and competences during the learning process. The implication of students in the development of the project will help them to think about concepts than simultaneously are being discussed in theory lessons and also to review those studied in past courses. Besides, not only it is a proof of this learning the implicit knowledge acquisition but also the final tangible product developed by the students.

This paper presents a new PBL experience designed for students of the Master of Science of Industrial Engineering at the Universitat Jaume I (Castellón de la Plana, Spain). The methodology is applied in the frame of the subject "Industrial construction and architecture". In this case, the activity consists on developing a project for the design and calculation of an industrial building. For each group of work, the tangible results of the project are a written manuscript and a poster where the structural proposal is schematically reflected. Each group exposes and defends its own solution to the rest of the class during the last session of the semester.

Next section describes the main aspects of the experience developed based on PBL which can be taken into account in the design of a similar activity. Nevertheless, since the project presented in this paper has been performed in the framework of a Master of Science of Industrial Engineering, some issues may need to be adapted when the activity is going to be implemented in another different context.

\section{Activity description}

The development of the activity starts with lecturers' implication in the planning and preparation of the experience. In this case, previous to the implementation of PBL, involved lecturers had several meetings to establish the objectives, the methodology and planning the different steps of the experience. Also during its development, periodic meetings were scheduled to comment the project and discuss any arising problems which enhance the coordination.

In order to design properly a PBL learning experience, the offered project must fulfill a series of requirements such as being significant and stimulating for the students and having well-defined objectives (Lacuesta et al., 2009). Besides, a certain grade of complexity may be assured in the sense of presenting a problem with different valid solutions and likely to be typical of the professional world.

Thus, the activity here described was designed to have these characteristics. Students had to be able to propose a competitive solution for a real necessity: the design and calculation of an industrial building. A structural project had to be developed taking into account the existence of multiple valid solutions, situation likely to be faced in their future careers. In 
fact, it is intended to recreate the environment of a technical office, simulating the pressure to present a competitive solution and satisfy the customer needs within a deadline.

In addition, for the sake of the good development of this learning method, it is recommended to involve a relative small number of students. Hence, the PBL methodology was implemented in a subject of a master where the number of students was small which facilitated to carry out with success the experience.

\subsection{Starting point}

The problem was presented and described to the students during one of the face-to-face lessons. Initial documentation was facilitated to the students by means of the virtual learning platform available at the university. The objective of the project was to design and calculate and industrial building optimizing its construction cost. The problem had some established conditions such as the location of the building and some geometrical aspects, simulating the costumer's desires. The structural project includes the design and calculation of all the main structural elements as well as the foundation.

In the same lesson, the students received some notions about the methodology to follow (PBL) and the evaluation system adopted. The working groups were created during this session with the assessment of the lecturer.

Finally, the students were informed about the final product: the final project documentation and a poster which schematically, but in an attractive manner, showed the proposal. All the material had to be delivered by means of the virtual learning platform, but the poster have also to be printed to be exposed in the final session. As recommended by other authors, guidance for this purpose was given in order to assure that the material produced by the groups had the same format and a certain level of homogeneity (Lacuesta et al., 2009).

\subsection{Initial analysis and research}

In this methodology, where learning is acquired through thinking and experience, the research work done by the students in the field of study is crucial. Students, both in an autonomous or in group form, must examine with detail the proposed problem and analyze the scenario. The base knowledge of students it is very important at this stage and it will be improved through the development of the project, with self-study and with the assessment of the lecturers. Literature review was encouraged at this point to extend the knowledge and references on this field. 


\subsection{Lecturer role}

In this student-centered learning methodology, lecturers assumed a secondary role in the sense that they became the engine of all the process that allows the students to develop the project; became observers and guides of the student learning process. Lecturers were information providers when the groups required it and supervised the continuous work of the students promoting always the critical thinking and the deliberation about the tasks done. Besides, during all the process, lecturers were aware of the learning process of the students, both individually and in group, as a part of the evaluation process.

\subsection{Interaction with the students and evaluation}

During the activity development, the different working groups met periodically to develop the project. Besides, tutorial sessions and a final session for the exhibition of the different proposals took place.

a. Working sessions: Working teams met to develop the project according to the scheduled tasks. As mentioned before, lecturers will check the progress of each group, answer questions and guide the students in the resolution of their doubts.

It is important to note that for the correct development of the activity and in order to facilitate the teamwork outside the university facilities, an educational license for software specialized in the design of steel structures was provided, so as the students could work on their project following their own schedules.

b. Tutorials: In these meetings, lecturers conversed with the students in order to examine the condition and quality of the work done by far.

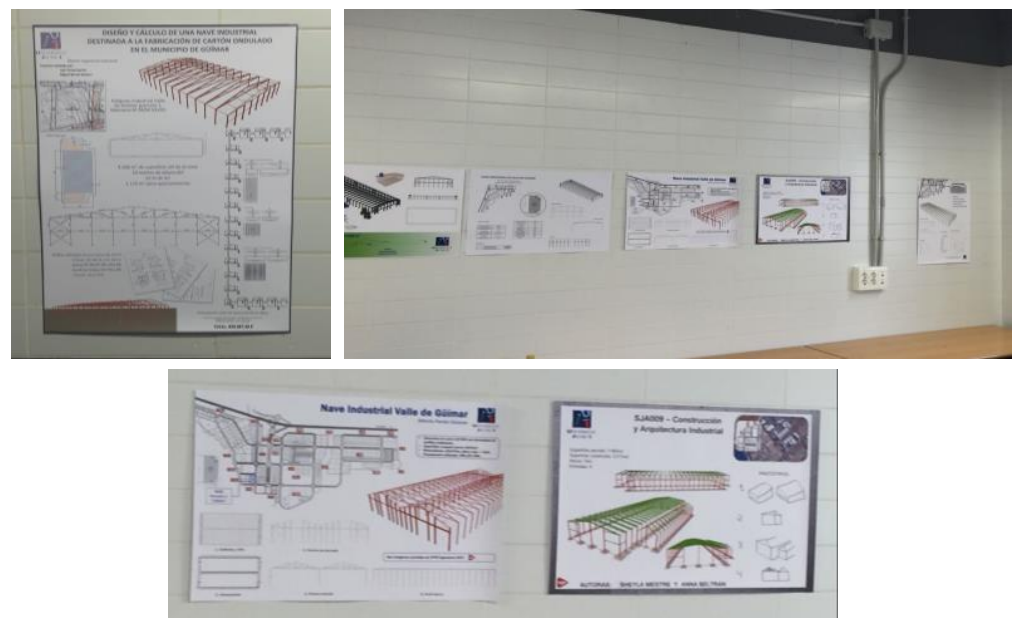

Figure 1. Exposition of posters with the different proposals. 
c. Group exhibitions: Each group presented its work to the rest of the students during the final session of the subject. The different proposals were exhibited by means of the posters produced (Figure 1). The session was organized trying to simulate the environment of a conference poster session. Each team explained the details of their proposal and after that, both lecturers and students, questioned them about it.

\subsection{Final assessment}

Since PBL is a methodology focused on the student, the evaluation process becomes especially relevant. Given the nature of the technique, the evaluation must be carried out both individually and on a group context. In this case, the evaluation consisted of:

a. Project assessment: for this subject, this mark is the $50 \%$ of the student's final mark (35\% final project, $15 \%$ oral defense) and is established by all the lecturers.

b. Individual evaluation: in this case, it corresponds to the $50 \%$ of the student's final mark. It covers mainly the individual student's learning and effort. Lecturers had done an individual monitoring of the student during the whole process and the registered information served to establish this mark.

\section{Results and discussion}

The analysis of this learning experience was performed thanks to the continuous assessment and the surveys carried out at the end of the activity. Some general aspects about the utility of the PBL as a learning technique were checked by means of a Yes/No section (Section A) of the survey. The aspects valuated were:

- A1. Adequacy of the subject embracing the project.

- A2. Necessity of technical concepts to develop the project.

- A3. The project complements the technical concepts treated in classroom lessons.

- A4. Proper duration of the project.

- A5. Adequacy of available material and resources.

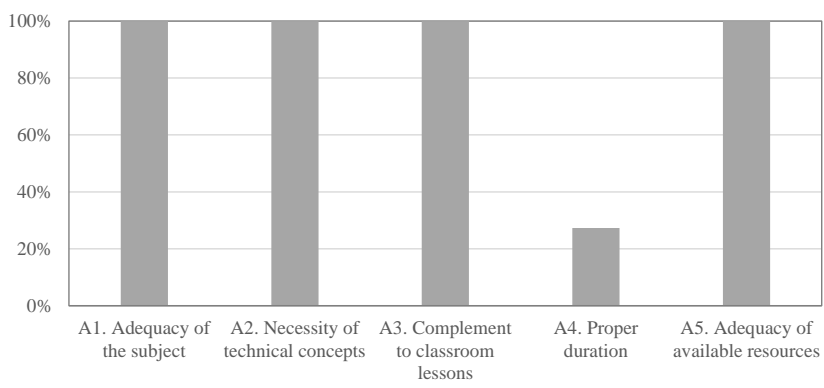

Figure 2. Student assessment of the utility of the PBL methodology. 
As shown in Figure 2, all the students considered that the subject was adequate to apply this methodology and were satisfied with the resources available. In addition, the students affirmed that technical concepts were essential to develop the project and so it served to complement the classrooms lessons and apply these concepts. However, only the $27 \%$ of the students considered that the deadline established was enough to develop properly the project. It is clear that adopting new techniques implies a change in their learning style and this adaptation takes time. Therefore, in order to control the time and effort that students invest in the project, lecturers should have paid more attention in that sense. For next experiences, some measures could be taken, such as for example limit the final report extension.

On the other hand, another section (Section B) valuated from 1 (lowest level) to 5 (highest level) tried to check the grade of achievement of the competences involved: continuous learning of technical knowledge (B1), autonomy (B2), teamwork (B3), communication (B4) and planning (B5) skills. Besides, this section included three more items:

- B6. Level of motivation in the development of the project.

- B7. Level of satisfaction with lecturer's attention.

- B8. How much do you recommend this type of experiences for other subjects?

In Table 1 and Figure 3, the qualifications given by the students are displayed. Whereas the students marked as satisfying (between 3 and 5) the level achieved in their capacity of learning to learn, autonomous work and planning skills, they considered that their aptitude of working in teams and communicate were not enhanced by this methodology. This fact points out the difficulty of developing these skills and the reason why they are highly appreciated by employers.

Table 1. Questions about the PBL methodology and level of achievement of skills.

\begin{tabular}{cc|cc|cc|cc}
\hline Question & Mean & Question & Mean & Question & Mean & Question & Mean \\
\hline B1 & $4.18 \pm 0.60$ & B3 & $2.89 \pm 1.62$ & B5 & $3.56 \pm 1.17$ & B7 & $4.89 \pm 0.30$ \\
B2 & $3.78 \pm 0.89$ & B4 & $2.56 \pm 1.48$ & B6 & $3.56 \pm 1.25$ & B8 & $3.89 \pm 1.14$ \\
\hline
\end{tabular}

However, answers to the last three items (B6, B7 and B8) show the high level of satisfaction of the students with the activity and with the lecturers attitude so as, in general, they recommend to apply the PBL methodology in other subjects. 


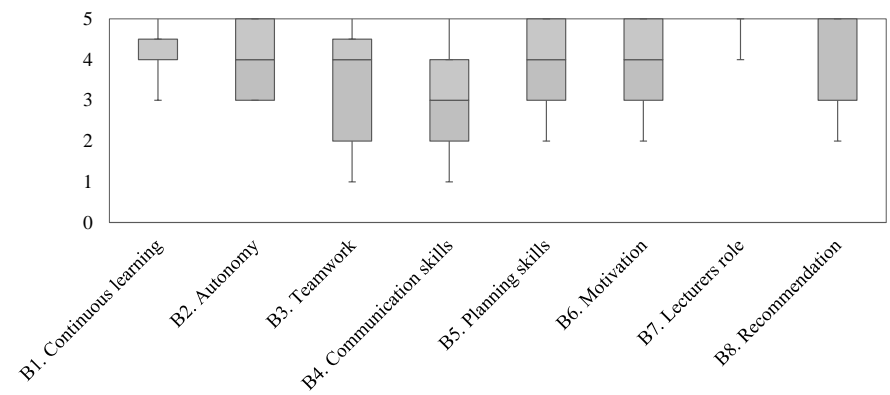

Figure 3. Results from questions about PBL methodology (see Table 1).

\section{Conclusions}

In conclusion, and although from the point of view of the lecturers, the implementation of this PBL experience involved much more effort that traditional learning, it can be said that both lecturers and students were highly motivated during its development and that great interest was observed in the students when this innovative activity was proposed. In fact, they recommended its implementation in other subjects.

Considering all, lecturers have planned to not only repeat this experience with master students next semester but also apply it to other subjects with undergraduate students in order to vary the student's profile to which the experience is addressed and improve the implementation of PBL methodology. 


\section{References}

Alcober, J., Ruiz, S., Valero, M. (2003). Evaluación de la implantación del aprendizaje basado en proyectos en la EPSC (2001-2003). XI Congreso Universitario de Innovación Educativa en las Enseñanzas Técnicas.

Bucharest Communiqué (2012). EHEA Bucharest Ministerial Conference. [Online] Available:http://media.ehea.info/file/2012_Bucharest/67/3/Bucharest_Communique_20 12 610673.pdf

De Miguel, M. (coord.) (2006). Metodologías de enseñanza y aprendizaje para el desarrollo de compentencias. Orientaciones para el profesorado universitario ante el Espacio Europeo de Educación Superior. Alianza Ed.

Gwen, S. (2003). Project-based learning: a primer. Technology and Learning, 23(6), 20-30.

Lacuesta, R., Palacios, G., Fernández, L. (2009). Active Learning through Problem Based Learning Methodology in Engineering Education. Frontiers in Education Conference $39^{\text {th }}$ IEEE

Maldonado, M. (2008). Aprendizaje basado en proyectos colaborativos. Una experiencia en Educación Superior. Revista de Educación, Laurus, 14 (28), 158-180.

Rodríguez, J., Laverón-Simavilla, A., del Cura, J.M., Ezquerro, J.M., Lapuerta, V., Cordero-Gracia, M. (2015). Project Based Learning experiences in the space engineering education at Technical University of Madrid. Advances in Space Research, 56, 1319-1330.

Tejero, J., Ramírez, E. Mata F., Harafi, J. (2015). La experiencia del aprendizaje basado en problemas y trabajos proyectuales en las asignaturas de Ingeniería de Estructuras en la Escuela de Ingeniería de Almadén. Innovación educativa en las enseñanzas técnicas, 2, 615-627.

Woods D.R., Felder R.M., Rugarcia, A., Stice, J.E. (2000). The future of engineering education. Developing critical skills. Chemical Engineering Education, 34(2), 108-117. 